\title{
Associations of Demographic and Socioeconomic Factors with Stage at Diagnosis of Breast Cancer
}

\author{
Pegah Mohaghegh ${ }^{1,2}$, Parvin Yavari ${ }^{1,2 *}$, Mohammad Esmail Akbari ${ }^{2}$, Alireza \\ Abadi $^{1}$, Farzane Ahmadi ${ }^{3}$
}

\begin{abstract}
Background: Stage at diagnosis is one of the most important prognostic factors of breast cancer survival. Because in the breast cancer case this may vary with socioeconomic characteristics, this study was performed to recognize the relationship between demographic and socioeconomic factors with stage at diagnosis in Iran. Materials and Methods: This cross-sectional, descriptive study conducted on 526 patients suffering from breast cancer and registered in Cancer Research Center of Shahid Beheshti University of Medical Sciences from 2008 to 2013. A reliable and valid questionnaire about family levels of socioeconomic status filled in by interviewing the patients via phone. For analyzing the data, Multinomial logistic regression, Kendal tau-b correlation coefficient and Contingency Coefficient tests were executed by SPSS22. Economic status, educational attainment of patient and household head and/or a combination of these were considered as parameters for socioeconomic status. First, the relationship between stage at diagnosis and demographic and socioeconomic status was assessed in univariate analysis then these relationships assessed in two different models of multinomial logistic regression. Results: The mean age of the patients was 48.3 (SD=11.4). According to the results of this study, there were significant relationships between stage at diagnosis of breast cancer with patient education $(p=0.011)$, living place $(p=0.044)$ and combined socioeconomic status $(p=0.024)$. These relationships persisted in multiple multinomial logistic regressions. Other variables, however, had no significant correlation. Conclusions: Patient education, combined socioeconomic status and living place are important variables in stage at diagnosis of breast cancer in Iranian women. Interventions have to be applied with the aim of raising women's accessibility to diagnostic and medical facilities and also awareness in order to reducing delay in referring. In addition, covering breast cancer screening services by insurance is recommended.
\end{abstract}

Keywords: Socioeconomic status - stage at diagnoses - breast cancer

Asian Pac J Cancer Prev, 16 (4), 1627-1631

\section{Introduction}

The long-term survival of women with breast cancer is dependent on the stage of disease at the time of diagnosis. Previous studies have indicated that survival of breast cancer among women with early stage at diagnosis of breast cancer is 90 percent while cancer diagnosis in late stages decreases the survival level to 60 percent (Harris and Leininger, 1995). Approximately 71 percent of Iranian women diagnose at late stage of breast cancer when curative therapies are less effective (Montazeri et al., 2003; Saadat et al., 2008; Namiranian et al., 2014; Xing et al., 2014). Harford, a member of National Cancer Institute of America in his study called "Breast-cancer early detection in low-income and middle-income countries: do what you can versus one size fits all" stated that in Egypt and other countries with low or middle income, women are diagnosed at a late stage of breast cancer (Harford, 2011).
Why these women aren't diagnosed sooner? Recognizing the barriers which cause delay in health care seeking in these women as well as the barriers within health care systems that contribute to failure to diagnose breast cancer earlier are important (Harford, 2011).

Stage at diagnosis of cancer is related to socioeconomic status, age, marital status, race and ethnicity (Roetzheim et al., 1999; Robin Yabroff and Gordis, 2003; Ali et al., 2008). Results of different studies show that presence and type of health insurance can be important factors (Halpern et al., 2007). The result of a systematic review in developing countries related to the factors which cause delay in health care seeking indicates strong evidences in favor of reference delay because of low education and income. The result of this study showed that poverty is the basic prevalent preventive determinant of early detection in these countries (Sharma et al., 2012). Therefore, knowing the determinants of stage at diagnosis of breast

${ }^{1}$ Department of Health and Community Medicine, School of Medicine, ${ }^{2}$ Cancer Research Center, ${ }^{3}$ Department of Biostatistics, Paramedical School, Shahid Beheshti University of Medical Science, Tehran, Iran *For correspondence: p.yavari-grc@sbmu. ac.ir,parvinyavari@yahoo.com 
cancer is an important variable in outcome improvement (Rastad et al., 2012). Recognizing the factors influencing delay in diagnosis and treatment is really important for policymakers to develop strategies to shorten delays (Rastad et al., 2012).

This study investigated the relationship between stage at diagnosis of breast cancer and demographic and socioeconomic factors.

\section{Materials and Methods}

This descriptive cross-sectional study conducted on 526 patients who were suffering from breast cancer and registered in Cancer Research Center of Shahid Beheshti University of Medical Sciences from March 2008 to December 2013. Primary data including name, call number, living place, family history of breast cancer, marital status and diagnostic data such as stage at diagnosis had been registered for each patient. The data about family socioeconomic status was gathered by interviewing the patients via phone and completing a questionnaire related to socioeconomic status. The questionnaire about socioeconomic status was the result of a study named "Socio-Economic Status in Iran: A study of measurement index" (Garmaroudi GH.R., 2010) for measuring family levels of socioeconomic status and its relationship with various health outcomes that its reliability and validity was measured. The determiner variables for family socioeconomic status in this questionnaire were Education of household head, patient's education, Economic conditions, including residential property, housing area per capita, and welfare convenience such as owning personal car and computer that were scored according to the people's answers. The maximum score for the questionnaire is 48 . Considering the median, the first, and the third quartiles, family socioeconomic status categorized to 4 levels: weak, moderate, good and excellent. The stage of breast cancer diagnosis was categorized from 1 to 4 according to the report of disease progression. Multinomial logistic regression, Kendal tau-b, and contingency coefficient were used for analyzing the data. Statistical analyses were performed by SPSS22 software. Patients' names were secret and their satisfactions for cooperating were gathered before commencing the study. Family's economic status, educational attainment of patient and household head and/or a combination of these were considered as socioeconomic status. First, the relationship between stage at diagnose and demographic and socioeconomic status assessed in univariate analysis then these relationships assessed in two different model of multinomial logistic regression.

\section{Results}

Out of 970 patients registered in Cancer Research Center of Shahid Beheshti University of Medical Sciences from March 2008 to December 2013, five hundred twenty six patients assisted the researcher and answered the questions related to socioeconomic status via phone. The mean age of the patients was $48.30(\mathrm{SD}=11.4)$. In total, 19.2 percent of patients were below 40 years old, and

Table 1. Multinomial Logistic Regression Results Examining the Relationship Between Stage at Diagnosis of Breast Cancer and Demographic and Socioeconomic Factors (Univariate Analysis)

\begin{tabular}{|c|c|c|c|c|c|c|}
\hline \multirow[t]{2}{*}{ Characteristics } & \multirow[t]{2}{*}{ Classification } & \multicolumn{3}{|c|}{ Stage of diagnosis } & \multirow[t]{2}{*}{ Test statistic 1,2} & \multirow[t]{2}{*}{ p-value } \\
\hline & & $\mathrm{I}$ & II & III/IV & & \\
\hline \multirow[t]{4}{*}{ Age at diagnosis } & $<40$ & $40(33.1)$ & $42(34.7)$ & $39(32.2)$ & -0.68 & 0.495 \\
\hline & $41-50$ & $77(36.8)$ & $81(38.8)$ & $51(24.4)$ & & \\
\hline & $51-60$ & $41(33.1)$ & $48(38.7)$ & $35(28.2)$ & & \\
\hline & $>60$ & $27(37.5)$ & $28(38.9)$ & $17(23.6)$ & & \\
\hline \multirow[t]{3}{*}{ Marital Status } & Single & $11(36.7)$ & $2(40.0)$ & $7(23.3)$ & 0.06 & 0.725 \\
\hline & Married & $167(34.8)$ & $180(37.5)$ & $133(27.7)$ & & \\
\hline & Divorced/widow & $7(43.8)$ & $7(43.8)$ & $2(12.5)$ & & \\
\hline \multirow[t]{3}{*}{ Education levels(Patient) } & Illiterate/Primary & $21(25.6)$ & $36(43.9)$ & $25(30.5)$ & -2.53 & 0.110 \\
\hline & Secondary / High school & $90(33.2)$ & $105(38.7)$ & $76(28.0)$ & & \\
\hline & Academic & $74(42.8)$ & $58(33.5)$ & $41(23.7)$ & & \\
\hline \multirow[t]{3}{*}{ Education levels(Household) } & Illiterate/Primary & $20(27.8)$ & $32(44.4)$ & $20(27.8)$ & -1.80 & 0.317 \\
\hline & Secondary / High school & $72(32.1)$ & $89(39.7)$ & $63(28.1)$ & & \\
\hline & Academic & $93(40.4)$ & $78(33.9)$ & $59(25.7)$ & & \\
\hline \multirow[t]{2}{*}{ Family history } & Yes & $58(34.7)$ & $70(41.9)$ & $39(23.4)$ & 0.07 & 0.317 \\
\hline & No & $127(35.4)$ & $129(35.9)$ & $103(28.7)$ & & \\
\hline \multirow[t]{4}{*}{ Economic status } & Weak $(\leq 9)$ & $36(31.9)$ & 47 (41.6) & $30(26.5)$ & -0.76 & 0.445 \\
\hline & Moderate (10-11) & $40(37.4)$ & $38(35.5)$ & $29(27.1)$ & & \\
\hline & Good (12-13) & $34(32.4)$ & $37(35.2)$ & $34(32.4)$ & & \\
\hline & Excellent ( $\geq 14)$ & $75(37.3)$ & $77(38.3)$ & $49(24.4)$ & & \\
\hline \multirow[t]{2}{*}{ Living place } & Tehran & $129(38.5)$ & $126(37.6)$ & $80(23.9)$ & 0.11 & $0.044 *$ \\
\hline & Others & $56(29.3)$ & $73(38.2)$ & $62(32.5)$ & & \\
\hline \multirow[t]{4}{*}{ Combined Socioeconomic status } & Weak $(\mathrm{SES} \leq 17)$ & $38(29.5)$ & $55(42.6)$ & $36(27.9)$ & -2.26 & $0.024 *$ \\
\hline & Moderate (18 to 21$)$ & $37(34.6)$ & $36(33.6)$ & $34(31.8)$ & & \\
\hline & Good (22 to 27$)$ & $44(30.8)$ & $60(42.0)$ & $39(27.3)$ & & \\
\hline & Excellent $(\mathrm{SES} \geq 28)$ & $66(44.9)$ & $48(32.7)$ & $33(22.4)$ & & \\
\hline
\end{tabular}

*1: Kendall's tau; 2: Contingency Coefficient. Significant variables are indicated with 
Associations of Demographic and Socioeconomic Factors With Stage at Diagnosis of Breast Cancer

13.7 percent were above 60 years old. Of the patients 15.6 percent were illiterate or had studied primary school, and 33 percent had academic education. Most of the patients, (63.7 percent) lived in Tehran and the others lived in the other cities.

Combined Socioeconomic status, and also economic status based on the median, the first and third quarters of patients' obtained scores via phone interview are divided into 4 levels which are presented in Table 1.

According to Table 1, there was a significant relationship between patient's educational level and stage at diagnosis of breast cancer $(\mathrm{p}=0.011)$. In other words, those patients with lower educational level were diagnosed at more advanced level of disease. Furthermore,

Table 2. Multiple Multinomial Logistic Regression Results Examining the Relationship between Stage at Diagnosis of Breast Cancer and Demographic and Socioeconomic Factors

\begin{tabular}{|c|c|c|c|c|c|c|}
\hline \multirow[t]{2}{*}{ Characteristics } & \multicolumn{3}{|c|}{ Stage II vs. stage I } & \multicolumn{3}{|c|}{ Stage III/IV vs. stage I } \\
\hline & Odds ratio & $95 \%$ confidence interval & $\overline{p-v a l u e}$ & Odds ratio & $95 \%$ confidence interval & $\mathrm{p}$-value \\
\hline \multicolumn{7}{|l|}{ Age at diagnosis } \\
\hline$<40$ & 1.25 & $0.57,2.73$ & 0.575 & 2.09 & $0.89,4.92$ & 0.092 \\
\hline $41-50$ & 1.47 & $0.77,2.83$ & 0.248 & 1.65 & $0.78,3.48$ & 0.191 \\
\hline $51-60$ & 1.14 & $0.58,2.22$ & 0.712 & 1.71 & $0.81,3.61$ & 0.163 \\
\hline$>60$ & 1 & Referent & & 1 & Referent & \\
\hline \multicolumn{7}{|l|}{ Marital Status } \\
\hline Single & 1.2 & $0.48,2.99$ & 0.703 & 0.87 & $0.30,2.49$ & 0.795 \\
\hline Married & 1 & Referent & & 1 & Referent & \\
\hline \multicolumn{7}{|c|}{ Educational levels(Patient) } \\
\hline Illiterate/Primary & 2.28 & $0.93,5.63$ & 0.073 & 2.70 & $1.01,7.3$ & $0.047 *$ \\
\hline Secondary/High school & 1.39 & $0.83,2.33$ & 0.208 & 1.50 & $0.85,2.63$ & 0.163 \\
\hline Academic & 1 & Referent & & 1 & Referent & \\
\hline \multicolumn{7}{|c|}{ Educational level (household head) } \\
\hline Illiterate/Primary & 1.31 & $0.57,0.76$ & 0.521 & 0.94 & $0.37,2.40$ & 0.903 \\
\hline Secondary/High school & 1.24 & $0.76,2.04$ & 0.394 & 1.10 & $0.64,1.88$ & 0.730 \\
\hline Academic & 1 & Referent & & 1 & Referent & \\
\hline \multicolumn{7}{|l|}{ Family history } \\
\hline Yes & 1.21 & $0.78,1.88$ & 0.397 & 0.82 & $0.50,1.34$ & 0.422 \\
\hline No & 1 & Referent & & 1 & Referent & \\
\hline \multicolumn{7}{|l|}{ Economic status } \\
\hline Weak & 1.03 & $0.57,1.85$ & 0.931 & 1.08 & $0.56,2.08$ & 0.819 \\
\hline Moderate & 0.72 & $0.41,1.29$ & 0.273 & 0.91 & $0.48,1.71$ & 0.766 \\
\hline Good & 0.94 & $0.53,1.68$ & 0.938 & 1.42 & $0.77,2.63$ & 0.261 \\
\hline Excellent & 1 & Referent & & 1 & Referent & \\
\hline \multicolumn{7}{|l|}{ Living place } \\
\hline Tehran & 0.78 & $0.51,1.23$ & 0.290 & 0.62 & $0.39,0.99$ & $0.046^{*}$ \\
\hline Others & 1 & Referent & & 1 & Referent & \\
\hline
\end{tabular}

Table 3. Multiple Multinomial Logistic Regression Results Examining the Relationship Between stage at Diagnosis of Breast Cancer and Demographic and Socioeconomic Factors

\begin{tabular}{|c|c|c|c|c|c|c|}
\hline \multirow[t]{2}{*}{ Characteristics } & \multicolumn{3}{|c|}{ Stage II vs. stage I } & \multicolumn{3}{|c|}{ Stage III/IV vs. stage I } \\
\hline & Odds ratio & $95 \%$ confidence interval & $\mathrm{p}$-value & Odds ratio & $95 \%$ confidence interval & $\mathrm{p}$-value \\
\hline \multicolumn{7}{|l|}{ Age at diagnosis } \\
\hline$<40$ & 0.95 & $0.46,1.96$ & 0.982 & 1.59 & $0.72,3.50$ & 0.253 \\
\hline $41-50$ & 1.17 & $0.64,2.14$ & 0.610 & 1.33 & $0.66,2.66$ & 0.422 \\
\hline $51-60$ & 0.97 & $0.51,1.86$ & 0.926 & 1.49 & $0.72,3.07$ & 0.285 \\
\hline$>60$ & 1 & Referent & & 1 & Referent & \\
\hline \multicolumn{7}{|l|}{ Marital Status } \\
\hline Single & 1.16 & $0.48,2.79$ & 0.746 & 0.76 & $0.28,2.11$ & 0.601 \\
\hline Married & 1 & Referent & & 1 & Referent & \\
\hline \multicolumn{7}{|l|}{ Family history } \\
\hline Yes & 1.25 & $0.81,1.94$ & 0.321 & 0.85 & $0.52,1.39$ & 0.501 \\
\hline No & 1 & Referent & & 1 & Referent & \\
\hline \multicolumn{7}{|l|}{ Living place } \\
\hline Tehran & 0.76 & $0.49,1.18$ & 0.221 & 0.60 & $0.37,0.95$ & $0.029 *$ \\
\hline Others & 1 & Referent & & 1 & Referent & \\
\hline \multicolumn{7}{|c|}{ Combined Socioeconomic status } \\
\hline Weak & 2.01 & $1.14,3.54$ & $0.016^{*}$ & 1.94 & $1.03,3.65$ & $0.040^{*}$ \\
\hline Moderate & 1.35 & $0.74,2.45$ & 0.329 & 1.90 & $1.01,3.60$ & $0.047 *$ \\
\hline Good & 1.88 & $1.09,3.24$ & $0.022 *$ & 1.70 & $0.93,3.12$ & 0.085 \\
\hline Excellent & 1 & Referent & & 1 & Referent & \\
\hline
\end{tabular}

*Stage I is regarded as the base. Significant variables are indicated with 
there was a significant relationship between stage at diagnosis of breast cancer and combined socioeconomic status $(p=0.024)$. It means that those people with lower socioeconomic status were diagnosed at more advanced stage of breast cancer. Also, the relationship between stage at diagnosis of breast cancer and living in Tehran was significant ( $\mathrm{p}=0.044$ ). Those people living in Tehran were diagnosed sooner rather than the other cities. In univariate analysis, Demographic variables including age and marital status had no significant correlation with stage at diagnose of breast cancer. Other variables, including family history of breast cancer, economic status and educational attainment of household head, had no significant correlation.

Table 2 shows that, the relationship between Stage III/ IV of breast cancer and patient's education, and also living in Tehran are significant. The odds of stage III/IV of breast cancer was 2.7 times higher in illiterate patients and those ones who studied primary school in comparison with those ones with academic education ( $\mathrm{p}=0.047)$. In addition, The odds of stage III/IV of breast cancer $38 \%$ lower in women who have lived in Tehran, in comparison with the others $(\mathrm{p}=0.046)$. We didn't observe any significant relationship between stage at diagnosis and other factors (Table 2).

According to Table 3, the odds of stage III/IV of breast cancer $40 \%$ lower in women who have lived in Tehran, in comparison with the others $(\mathrm{p}=0.029)$. In patients with low socioeconomic status the odds of stage 2 of breast cancer were 2 times higher than women with excellent socioeconomic status $(\mathrm{p}=0.016)$ and the odds of stage III/ IV of breast cancer were 1.94 times higher than women with excellent socioeconomic status $(\mathrm{p}=0.040)$.

The odds of stage III/IV of breast cancer was $90 \%$ higher in women with moderate socioeconomic status in comparison with excellent socioeconomic status $(\mathrm{p}=0.047)$. In patients with good socioeconomic status the odds of stage 2 of breast cancer were 1.88 times higher than women with excellent socioeconomic status $(\mathrm{p}=0.022)$. In this model there weren't any significant relationship between stage at diagnosis and age, marital status, and family history.

\section{Discussion}

According to the results of this study the mean age of patients was $48.30(\mathrm{SD}=11.41)$ with the range of 21 to 90 years old and the median age was 48 . In the study of Yavari et al, the mean age of patients was 48.8 ( $\mathrm{SD}=9.8)$ (Yavari et al., 2005). Also in the research of Movahedi et al the mean age of patients was $49.8(\mathrm{SD}=12.3)$ (Movahedi et al., 2012), and in the study of Ebrahimi et al, the mean age of patients was 46.2 (Ebrahimi, 2002). These finding is similar to the result from previous studies.

In this study, there was a significant relationship between stage at diagnosis of breast cancer and combined socioeconomic status $(\mathrm{p}=0.024)$. It means that people with poor socioeconomic status were diagnosed at late-stage of disease. This association in multiple multinomial logistic regressions after adjusting the effects of age, marital status, family history of breast cancer and living place, was significant. Harirchi et al found that low income is one of the causes of having delay in referring women with advanced breast cancer (Harirchi et al., 2005). Richardson et al have found that low socioeconomic status is one of the risk factors of late stage diagnosis of breast cancer and patients' referring (Richardson et al., 1992). Kafashian et al indicated stage at diagnosis correlated with poorer prognosis in women with lower socioeconomic status (Kaffashian et al., 2003).

In this study, the relationship between stage at diagnosis and living in Tehran was significant. Harirchi et al found that living in small cities and lack of access to healthcare systems and health facilities contribute to have delay in referring patients with advanced level of breast cancer (Harirchi et al., 2005). According to the results of Mackinon et al, living place has an important role in defining risk of advanced breast cancer (MacKinnon et al., 2007). Banquet et al found that socioeconomic status more than race can predict the possibility of people's and group's accessibility to education, specific jobs and health insurance and all of them are related to later diagnosis and cancer survival (Baquet, 2000).

According to the result of this study, there is a significant relationship between stage at diagnosis and patient's education $(p=0.011)$. In other words, those ones with lower educational level are referred at more advanced level of disease. This relationship was also significant in multiple logistic regression $(\mathrm{p}=0.047)$. Previous studies have demonstrated that lower education and income are the most important causes of delay in diagnosis of breast cancer in women in developing countries (Ali et al., 2008; Sharma et al., 2012). Harirchi et al also found that lower education is one of the most important causes of delay in referring to practitioners with advanced level of cancer (Harirchi et al., 2005). In our study, there was no significant relationship between stage at diagnosis of breast cancer and marital status, age at diagnosis, family history of breast cancer, economic status and Education of household head. Several studies have shown that advanced age is an important factor for admission with late stage breast cancer and patients with metastasis at the time of diagnosis were older than other patients (Ermiah et al., 2012; Ghazali et al., 2013; Uyeturk et al., 2013). Although, Richardson et al indicated that one of the causes of late stage diagnosis of breast cancer and having delay in patient's referring to physician was being younger (Richardson et al., 1992). Harirchi et al found that having delay in referring to physician was associated with being married and negative family history of breast cancer (Harirchi et al., 2005). The results of a study in Malaysia showed that divorced or widowed women had a higher risk of delayed presentation than married women (Ghazali et al., 2013).

There were some limitations in this study. The possibility of recall bias was an issue as some Women might have wrongly estimated socioeconomic status before diagnose of breast Cancer. Additionally, this research has conducted in a university (teaching) hospital, so the results might not be extended to all Iranian women.

In conclusion, Patient's education, combined socioeconomic status and also living place are important variables in stage at diagnosis of breast cancer. 
Interventions have to be applied with the aim of raising people's accessibility to diagnostic and medical facilities and also women's awareness in order to reducing delay in referring. In addition, covering breast cancer screening services by insurance is recommended.

\section{Acknowledgements}

This research was funded by a grant from the Cancer Research Center of Shahid Beheshti University of Medial Sciences. Writers thank the Cancer Research Center of Shahid Beheshti University of Medial Sciences, especially Zeinab Shormeig for providing primary data for our study. We also extent our thanks to all the patients and their relatives for their cooperation with the researchers.

\section{References}

Ali R, Mathew A, Rajan B (2008). Effects of socio-economic and demographic factors in delayed reporting and late-stage presentation among patients with breast cancer in a major cancer hospital in South India. Asian Pac J Cancer Prev, 9, 703-7.

Baquet CR, Commiskey P (2000). Socioeconomic factors and breast carcinoma in multicultural women. Cancer, 88,1256-64.

Ebrahimi M, Vahdania M, Montazeri A (2002). Risk factors for breast cancer in Iran. A case- control study. Breast Cancer Res, 4, 22-26.

Ermiah E, Abdalla F, Buhmeida A, et al (2012). Diagnosis delay in Libyan female breast cancer. BMC Res Notes, 5, 452-460.

Garmaroudi GHR, Moradi A (2010). Socio-Economic Status in Iran: A study of measurement index [abstract]. Payesh, 9, 137-144.

Ghazali SM, Othman Z, Cheong KC, et al (2013). Non-practice of breast self examination and marital status are associated with delayed presentation with breast cancer. Asian Pac J Cancer Prev, 14, 1141-5.

Halpern MT, Bian J, Ward EM, Schrag NM, Chen AY (2007). Insurance status and stage of cancer at diagnosis among women with breast cancer. Cancer, 110, 403-11.

Harford JB (2011). Breast-cancer early detection in low-income and middle-income countries: do what you can versus one size fits all. Lancet Oncol, 12, 306-312.

Harirchi I, Ghaemmaghami F, Karbakhsh M, Moghimi R, Mazaherie H (2005). Patient delay in women presenting with advanced breast cancer: an Iranian study. Public Health, 119, 885-891.

Harris R, Leininger L (1995). Clinical strategies for breast cancer screening: weighing and using the evidence. Ann Internal Med, 122, 539-547.

Kaffashian F, Godward S, Davies T, et al (2003). Socioeconomic effects on breast cancer survival: proportion attribuTable to stage and morphology. Br J Cancer, 89,1693-6.

MacKinnon JA, Duncan RC, Huang Y, Lee DJ, Fleming LE, Voti L, et al (2007). Detecting an association between socioeconomic status and late stage breast cancer using spatial analysis and area-based measures. Cancer Epidemiol Biomarkers Prev, 16, 756-62.

Montazeri A, Ebrahimi M, Mehrdad N, Ansari M, Sajadian A (2003). Delayed presentation in breast cancer: a study in Iranian women. BMC Women's Health, $\mathbf{3}, 4$.

Movahedi M, Haghighat S, Khayamzadeh M, Moradi A, Ghanbari-Motlagh A, Mirzaei H, et al (2012). Survival rate of breast cancer based on geographical variation in iran, a national study. Iran Red Crescent Med J, 14, 798-804.

Namiranian N, Moradi-Lakeh M, Razavi-Ratki K, Doayie M, Nojomi M (2014). Risk factors of breast cancer in the eastern mediterranean region: a systematic review and metaanalysis. Asian Pac J Cancer Prev, 15, 9535-41.

Rastad H, Khanjani N, Khandani BK (2012). Causes of delay in seeking treatment in patients with breast cancer in Iran: a qualitative content analysis study. Asian Pac J Cancer Prev, 13, 4511-5.

Richardson JL, Langholz B, Bernstein L, et al (1992). Stage and delay in breast cancer diagnosis by race, socioeconomic status, age and year. Br J Cancer, 65, 922-6.

Robin Yabroff K, Gordis L (2003). Does stage at diagnosis influence the observed relationship between socioeconomic status and breast cancer incidence,case-fatality, and mortality? Soc Sci Med, 57, 2265-79.

Roetzheim RG, Pal N, Tennant C, Voti L, Ayanian JZ, Schwabe A, et al (1999). Effects of health insurance and race on early detection of cancer. J Natl Cancer Inst, 91, 1409-15.

Saadat M, Kohan L, Omidvari S (2008). Genetic polymorphisms of XRCC1 (codon 399 and susceptibility to breast cancer in Iranian women, a case-control study. Breast cancer res treat, 111, 549-53.

Sharma K, Costas A, Shulman LN, Meara JG (2012). A systematic review of barriers to breast cancer care in developing countries resulting in delayed patient presentation. J Oncol, 2012, 121873.

Uyeturk U, Tatli AM, Gucuk S, et al (2013). Risk factors for stage IV breast cancer at the time of presentation in Turkey. Asian Pac J Cancer Prev, 14, 7445-9.

Yavari P, Mosavizadeh M, Sadrol-Hefazi B, Mehrabi Y (2005). Reproductive characteristics and the risk of breast cancer -a case-control study in Iran. Asian Pac J Cancer Prev, 6, 370-5.

Xing MY, Xu SZ, Shen P (2014). Effect of low-fat diet on breast cancer survival: a meta-analysis. Asian Pac J Cancer Prev, 15, 1141-4. 